\title{
Septic arthritis in children: diagnosis and treatment
}

This article was published in the following Dove Press journal:

Pediatric Health, Medicine and Therapeutics

18 May 2017

Number of times this article has been viewed

\section{Markus Pääkkönen ${ }^{1,2}$ \\ 'Department of Pediatric Orthopaedic Surgery, ${ }^{2}$ Department of Hand Surgery, Turku University Hospital and the University of Turku, Turku, Finland}

\begin{abstract}
Acute septic arthritis in children is usually hematogenous. It is more common in boys, and it most often affects the large joints of the lower limb. Diagnosis is based on cultures obtained from the infected joint and is supported by C-reactive protein blood test or ultrasound imaging. Staphylococcus aureus is the most common causative agent and is the primary target for empiric treatment. First-generation cephalosporins and clindamycin are suitable antibiotics. Vancomycin is utilized in areas with high rates of clindamycin- and methicillin-resistant S. aureus. After a short intravenous administration of 2-4 days, a total course of 2 weeks is sufficient in uncomplicated cases. Early antibiotic treatment has significantly improved the prognosis in high-income settings, but uncomplicated recovery is compromised if the treatment is delayed. Complications such as symptomatic osteoarthritis or avascular necrosis of the femoral head develop slowly. A long follow-up of 1-2 years is required to detect all possible sequelae.

Keywords: child, septic arthritis, sepsis, Staphylococcus aureus
\end{abstract}

\section{Introduction}

Acute septic arthritis (SA) in children is most often a hematogenous infection. ${ }^{1,2}$ The sluggish blood flow in the metaphyseal capillaries makes growing bones susceptible to infection from hematogenous seeding from any trauma or infection. SA is more common in boys than girls with a ratio of $2: 1 .^{1,2}$ The incidence in developed countries is 4-5 cases per 100000 children per year. ${ }^{1}$ Most commonly affected locations in the body are the large joints of the lower limb - hip, knee, and ankle joints. Staphylococcus aureus and respiratory pathogens are the most common causative agents. Kingella kingae is a regional pathogen that has increasingly been identified as a common causative agent especially in children aged 6-36 months. ${ }^{3}$ The role of trauma in the pathogenesis remains unclear. ${ }^{4}$ In neonates, bacteria such as Escherichia coli is frequently encountered in birth canal.

\section{Diagnosis}

Even though acute SA can present in a variety of ways, the classic presentation is an acutely swollen, red, painful joint with limited motion and fever. The child refuses weight-bearing if the lower limb is involved. Neonates with a septic hip assume a characteristic position with the hip joint flexed and abducted in internal rotation. Fever is especially high in cases caused by methicillin-resistant $S$. aureus (MRSA). ${ }^{5}$ Cases caused by $K$. kingae are milder, and fever may even be absent. ${ }^{6}$ The disease may be insidious, as any joint in the body may be affected, and immunocompromise,
Correspondence: Markus Pääkkönen Department of Pediatric Orthopaedic Surgery, Turku University Hospital and the University of Turku, Kiinamyllynkatu 4-8, PL 52, 2052I Turku, Finland $\mathrm{Tel}+35823130000$

Fax +35823133613

Email Markus.Paakkonen@helsinki.fi 
Table I Conditions to be considered in the differential diagnosis of septic arthritis of childhood

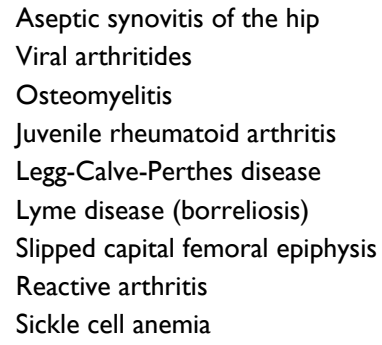

immunosuppression, or recent use of antibiotics can alter the clinical and laboratory appearance of a septic joint. Differential diagnosis includes osteomyelitis, viral arthritides, and juvenile rheumatoid arthritis (Table 1). Serum C-reactive protein (CRP), white blood cell count (WBC), and erythrocyte sedimentation rate (ESR) are used to differentiate transient hip synovitis from septic hip arthritis, although overlap exists between the conditions. ${ }^{6,7}$

The diagnostic algorithm for SA is shown in Figure 1. If a child with acute symptoms has elevated CRP $(>20 \mathrm{mg} / \mathrm{L})^{8}$ or ESR ( $>20 \mathrm{~mm} / \mathrm{h}$ ) values, a joint puncture is performed to detect any purulent aspirate and obtain a sample for bacteriology. Blood cultures are obtained. Synovial fluid findings are unspecific, but a synovial fluid sample with WBC of $>50000 / \mu \mathrm{L}$ of which $>75 \%$ are polymorphonuclear cells is considered to suggest SA. ${ }^{8}$ Cultures may remain negative even in $30-70 \%$ of the cases. ${ }^{1,9}$ In addition to agar plates, it is advisable to culture synovial fluid in aerobic blood culture bottles to improve the detection of $K$. kingae. Plain X-ray is not very useful in diagnosis, but it may detect joint swelling or chronic osteomyelitis. Ultrasound may be used to detect joint swelling and to guide joint puncture. Magnetic resonance imaging does show swelling and is particularly useful in diagnosing adjacent osteomyelitis or an abscess, but it does require anesthesia in infants.

\section{Treatment}

Treatment is started without delay after synovial fluid and blood samples have been obtained. Empiric treatment primarily targets $S$. aureus and takes into account its resistance to antibiotics (Table 2). First-generation cephalosporins and clindamycin are both suitable, but these should be administered in large doses and 4 times a day as these are time-dependent antibiotics. ${ }^{10}$ In regions where prevalence of MRSA strains exceeds $10 \%$, clindamycin is a valid option of treatment if prevalence of clindamycin-resistant strains remains $<10 \%$. If clindamycin resistance is common, vancomycin is the first option of treatment, despite concerns over poor bone penetration. ${ }^{11}$ Penicillin monotherapy is suitable
Table 2 Recommended empiric antibiotic treatment

\begin{tabular}{|c|c|}
\hline $\begin{array}{l}\text { Local resistance patterns of } \\
\text { Staphylococcus aureus }\end{array}$ & Choice of antibiotics \\
\hline$>90 \%$ methicillin sensitive & $\begin{array}{l}\text { First-generation cephalosporin or } \\
\text { clindamycin }\end{array}$ \\
\hline$<90 \%$ methicillin sensitive & Clindamycin \\
\hline $\begin{array}{l}<90 \% \text { methicillin sensitive and } \\
<90 \% \text { clindamycin sensitive }\end{array}$ & Vancomycin \\
\hline Vancomycin resistance & Linezolid \\
\hline
\end{tabular}

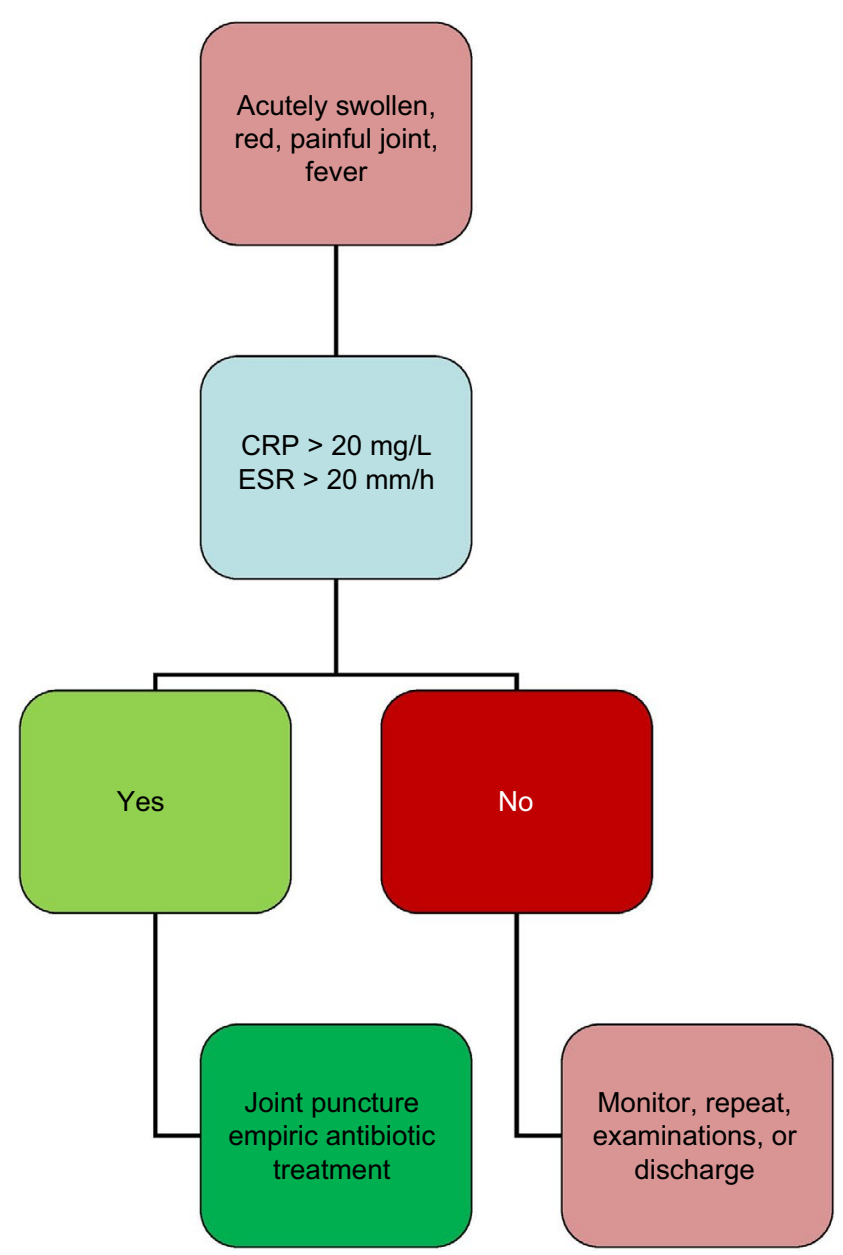

Figure I The diagnostic algorithm for childhood septic arthritis. Abbreviations: CRP, C-reactive protein; ESR, erythrocyte sedimentation rate.

for Streptococcus pyogenes and S. pneumoniae, provided that large doses are given. ${ }^{12}$ Children who have received a Haemophilus type $b$ vaccination do not require adjuvant ampicillin or amoxicillin, which in the prevaccination era was often given to all children under 5 years of age. ${ }^{13} \mathrm{~K}$. kingae is susceptible to most penicillins and cephalosporins. ${ }^{14}$ Fluoroquinolones or third-generation cephalosporins are valid options against Salmonella spp., but the cost may be a problem in low-income settings. ${ }^{15,16}$

In figure 2, it shows the optimal length of antibiotic treatment for acute SA. After a short 2-4 day intravenous course, the antibiotic may be administered orally if the patient is 


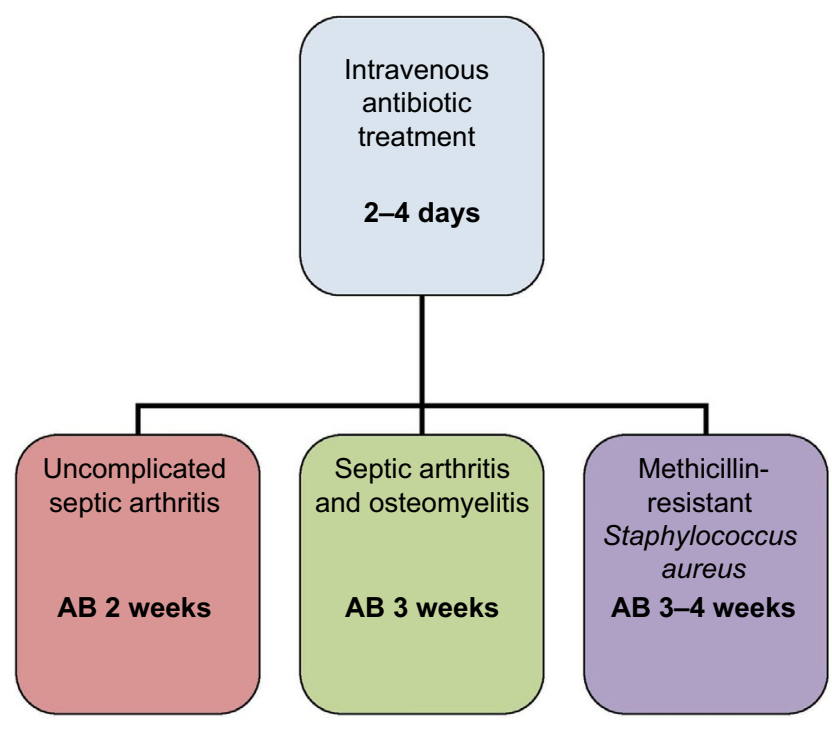

Figure 2 The duration of antibiotic $(A B)$ treatment for childhood septic arthritis.

recovering and CRP level is declining. ${ }^{10} \mathrm{~A}$ total course of 2 weeks is sufficient in uncomplicated cases. ${ }^{17}$ If an adjacent bone is involved, the antibiotic treatment should be extended to last at least for 3 weeks. ${ }^{18}$ Dexamethasone can be administered to reduce inflammation and may lead to slightly shorter hospital stay. ${ }^{19}$ Nonsteroidal anti-inflammatory agents are administered for pain relief.

\section{Monitoring}

Sequential CRP measurements offer useful information in monitoring recovery. ${ }^{4}$ ESR reacts too slowly to changes in the clinical course of illness to be useful in the follow-up. $\mathrm{CRP}<20 \mathrm{mg} / \mathrm{L}$ is a strong indicator of recovery and informs the clinician that the antibiotics can be safely stopped. ${ }^{8,10}$ Delayed diagnosis, sickle cell disease, and infection caused by Panton-Valentine leucocidin-producing strains of MRSA are considered to predispose to orthopedic sequelae, ${ }^{20,21}$ and a prolonged course of 3-4 weeks for MRSA SA is still recommended by most researchers. ${ }^{11}$ Also, the optimal length of antibiotic therapy has not been studied in patients with immunodeficiency and severe underlying illness and in the neonates, and in these cases, the therapy may have to be individualized.

\section{Surgery}

Drainage of pus from an infected joint can be accomplished by joint puncture, arthroscopy, or open arthrotomy. Although traditionally open arthrotomy was recommended for hip arthritis, several publications have shown mini-invasive methods to be a safe alternative. ${ }^{22,23}$ Open arthrotomy can be reserved for cases that do not respond to repeated aspirations. Arthroscopy has gained popularity in knee, hip, and shoulder arthritis. ${ }^{24,25}$

\section{Long-term sequelae}

Relapses or reinfections are rare if large-dose short-course antibiotic treatment has been administered. ${ }^{10,17}$ Feared complication of septic hip arthritis is the avascular necrosis of the femoral head. ${ }^{21}$ Among infants, joint effusion can result in the dislocation of the hip joint and may lead to instability requiring hip spica casting. Cartilage destruction leads to symptomatic osteoarthritis in an affected joint. The complications may develop slowly, and a long follow-up of 1-2 years may be required to detect all possible sequelae.

\section{Conclusion}

All children presenting with symptomatic joint and fever should be suspected to have SA. Diagnosis is confirmed by a joint puncture, and a sample for bacteriology is obtained before intravenous antibiotics are administered. Intravenous course is continued for 2-4 days until recovery is observed. A total course of 2 weeks is sufficient in uncomplicated cases. Open arthrotomy is reserved for patients who do not respond to conventional therapy. Patients with delayed diagnosis or MRSA infection carry a poorer prognosis, as do non-privileged children in low-income settings. ${ }^{26}$

\section{Disclosure}

The author reports no conflicts of interest in this work.

\section{References}

1. Krogstad P. Osteomyelitis and septic arthritis. In: Feigin RD, Cherry JD, editors. Textbook of Pediatric Infectious Diseases. 6th ed. Philadelphia, PA: Saunders; 2009:725-748.

2. Pääkkönen M, Peltola H. Management of a child with suspected acute septic arthritis. Arch Dis Child. 2012;97(3):287-292.

3. Yagupsky P. Kingella kingae: carriage, transmission, and disease. Clin Microbiol Rev. 2015;28(1):54-79.

4. Pääkkönen M, Kallio MJ, Lankinen P, Peltola H, Kallio PE. Preceding trauma in childhood hematogenous bone and joint infections. J Pediatr Orthop B. 2014;23(2):196-199.

5. Ju KL, Zurakowski D, Kocher MS. Differentiating between methicillinresistant and methicillin-sensitive Staphylococcus aureus osteomyelitis in children: an evidence-based clinical prediction algorithm. $J$ Bone Joint Surg Am. 2011;93(18):1693-1701.

6. Yagupsky P, Dubnov-Raz G, Gené A, Ephros M; Israeli-Spanish Kingella kingae Research Group. Differentiating Kingella kingae septic arthritis of the hip from transient synovitis in young children. J Pediatr. 2014;165(5):985-989.

7. Sultan J, Hughes PJ. Septic arthritis or transient synovitis of the hip in children: the value of clinical prediction algorithms. J Bone Joint Surg Br. 2010;92(9):1289-1293.

8. Pääkkönen M, Kallio MJ, Kallio PE, Peltola H. Sensitivity of erythrocyte sedimentation rate and C-reactive protein in childhood bone and joint infections. Clin Orthop Relat Res. 2010;468(3):861-866.

9. Lyon RM, Evanich JD. Culture-negative septic arthritis in children. J Pediatr Orthop. 1999;19(5):655-659.

10. Peltola H, Pääkkönen M, Kallio P, Kallio MJ; OM-SA Study Group Clindamycin vs. first-generation cephalosporins for acute osteoarticular infections of childhood - a prospective quasi-randomized controlled trial. Clin Microbiol Infect. 2012;18(6):582-589. 
11. Liu C, Bayer A, Cosgrove SE, et al; Infectious Diseases Society of America. Clinical practice guidelines by the Infectious Diseases Society of America for the treatment of methicillin-resistant Staphylococcus aureus infections in adults and children. Clin Infect Dis. 2011;52(3):e18-e55.

12. Mera RM, Miller LA, Amrine-Madsen H, Sahm DF. Impact of new clinical testing laboratory standards institute Streptococcus pneumoniae penicillin susceptibility testing breakpoints on reported resistance changes over time. Microb Drug Resist. 2011;17(1):47-52.

13. Peltola H, Kallio MJT, Unkila-Kallio L. Reduced incidence of septic arthritis in children by Haemophilus influenza type-b vaccination. Implications for treatment. J Bone Joint Surg Br. 1998;80(3):471-473.

14. Saphyakhajon P, Joshi AY, Huskins WC, Henry NK, Boyce TG. Empiric antibiotic therapy for acute osteoarticular infections with suspected methicillin-resistant Staphylococcus aureus or Kingella. Pediatr Infect Dis J. 2008;27(8):765-767.

15. Sherman JW, Conte JE Jr. Ceftriaxone treatment of multidrug-resistant salmonella osteomyelitis. Am J Med. 1987;83(1):137-138.

16. Bradley JS, Jackson MA; Committee on Infectious Diseases; American Academy of Pediatrics. The use of systemic and topical fluoroquinolones. Pediatrics 2011;128(4):e1034-e1045.

17. Peltola H, Pääkkönen M, Kallio P, Kallio MJ; Osteomyelitis-Septic Arthritis (OM-SA) Study Group. Prospective, randomized trial of 10 days versus 30 days of antimicrobial treatment, including a short-term course of parenteral therapy, for childhood septic arthritis. Clin Infect Dis. 2009;48(9):1201-1210.
18. Peltola H, Pääkkönen M. Acute osteomyelitis in children. $N$ Engl J Med. 2014;370(4):352-360.

19. Fogel I, Amir J, Bar-On E, Harel L. Dexamethasone therapy for septic arthritis in children. Pediatrics. 2015;136(4):e776-e782.

20. Carrillo-Marquez MA, Hulten KG, Hammerman W, Mason EO, Kaplan SL. USA300 is the predominant genotype causing Staphylococcus aureus septic arthritis in children. Pediatr Infect Dis J. 2009;28(12):1076-1080.

21. Ilharreborde B. Sequelae of pediatric osteoarticular infection. Orthop Traumatol Surg Res. 2015;101(1 Suppl):S129-S137.

22. Givon U, Liberman B, Schindler A, Blankstein A, Ganel A. Treatment of septic arthritis of the hip joint by repeated ultrasound-guided aspirations. J Pediatr Orthop. 2004;24(3):266-270.

23. Pääkkönen M, Kallio MJ, Peltola H, Kallio PE. Pediatric septic hip with or without arthrotomy: retrospective analysis of 62 consecutive nonneonatal culture-positive cases. J Pediatr Orthop B. 2010;19(3): 264-269.

24. Agout C, Lakhal W, Fournier J, de Bodman C, Bonnard C. Arthroscopic treatment of septic arthritis of the knee in children. Orthop Traumatol Surg Res. 2015;101(8 Suppl):S333-S336.

25. Edmonds EW, Lin C, Farnsworth CL, Bomar JD, Upasani VV. A medial portal for hip arthroscomy in children with septic arthritis: a safety study. J Pediatr Orthop. Epub 2016 Sep 3.

26. Lavy CB. Septic arthritis in Western and sub-Saharan African children a review. Int Orthop. 2007;31(2):137-144.
Pediatric Health, Medicine and Therapeutics

\section{Publish your work in this journal}

Pediatric Health, Medicine and Therapeutics is an international, peerreviewed, open access journal publishing original research, reports, editorials, reviews and commentaries. All aspects of health maintenance, preventative measures and disease treatment interventions are addressed within the journal. Practitioners from all disciplines are invited to submit

\section{Dovepress}

their work as well as healthcare researchers and patient support groups The manuscript management system is completely online and includes a very quick and fair peer-review system. Visit http://www.dovepress.com/ testimonials.php to read real quotes from published authors. 